\title{
Promising technology for reusable harvesting tomatoes
}

\author{
Viktor A.Ablikov ${ }^{1, *}$, Viktor $V$. Moiseev ${ }^{1}$, and Sergey A. Pomelyiko ${ }^{1}$ \\ ${ }^{1}$ FSBEI HE Kuban State Agrarian University named after I.T.Trubilin, Krasnodar, Russian Federation
}

\begin{abstract}
The work is devoted to harvesting tomatoes both direct and reusable way. The article is of a research nature, which is expressed in the fact that there were shown the analysis of tomato harvesting of different varieties, as well as excerpts from the works of leading scientists on the problem, their shortcomings and ways of solving these problems were specified. The main tendency of equipment developments and updating of its design for improvement of quality characteristics of their work was defined. Also, there was given proof the type of the suggested design, its description and the flow of the technological process. As a result of the work done, the design of the device for reusable harvesting of tomatoes and nightshade vegetables with the suggested working elements is presented. The conclusions set out the main results achieved so far.
\end{abstract}

Vegetable growing is an important branch of agricultural production. Of many vegetable plants, increasing importance is attached to crops whose products contain physiologically active substances. These crops include nightshade vegetables. In Russia vegetables are industrially cultivated in the south of the country. Everywhere in Russia vegetable growing is reduced. This is due to high production costs, especially for harvesting, which, with a general shortage of manual labor, leads to a reduction in areas, violation of the technology of cultivation and harvesting and, accordingly, to a decrease in productivity. The maximum mechanization of the technological process of vegetables harvesting will be required in the conditions of import substitution of foreign agricultural products and increasing the areas of planting vegetables in the Russian Federation to create a safety cushion. The most important results of the types of designs of vegetable harvesters and the problems of using modern devices for harvesting vegetables are presented [1].

Physical and mechanical properties of tomatoes have been studied sufficiently. We research only those that are important in the process of mechanized harvesting.

The following schemes of plant layout in the field: $90 \times 50 ; 100 \times 40 ; 120 \times 60$ are used for mechanized harvesting. The deviation of plant bottoms from the axis of a row during the harvesting period is $+10 \mathrm{~cm}$, the width of the shrubs' crown is $40-90 \mathrm{~cm}$, the average height of shrubs is $30-50 \mathrm{~cm}$. At harvesting time the number of vegetables located in the area of 0 $100 \mathrm{~mm}$ from the surface of the field is $65-90 \%$, up to $15 \%$ of vegetables are on the ground. The weight of plants with vegetables varies from 0.5 to $4.0 \mathrm{~kg}$, the weight of

\footnotetext{
* Corresponding author: sergey belousov87@mail.ru
} 
vegetables on a shrub is from 0.2 to $2.8 \mathrm{~kg}$, varieties with small and medium vegetables (vegetable diameter $20-60 \mathrm{~mm}$ ) are used for machine harvesting [2].

The total losses of standard tomatoes which remain behind the harvester should not exceed $10 \%$, including fruits with mechanical damage and clogged in a heap - no more than $5 \%$. Soil impurities in the heap should be no more than $5 \%$, plant residues and other impurities - no more than $0.5 \%$.

Only those varieties of tomatoes that meet the following basic requirements are suitable for one-time harvesting:

- $\quad$ high crop productivity and simultaneity of tomatoes maturing;

- $\quad$ tomatoes resistance to statistic and dynamic loads;

- $\quad$ provision of tomatoes separation from plants without stalk;

- $\quad$ presence of compact non-lodged shrub;

- $\quad$ high biochemical rates of tomatoes;

- $\quad$ tomatoes resistance to overripe.

The damage of tomatoes (strength characteristics), the effort of separation of tomatoes from the stalk, the strength of the connection of a shrub with soil, the effort of breaking the stalk, the lodging of shrubs, the simultaneity of ripening, transportability and keeping capacity, spectral characteristics and others are the technological properties of tomatoes which are important for mechanical harvesting [3].

Fruit damage largely depends on the strength of fruit, due to the strength of skin, its elasticity and density of pulp. Fruit with strong skin have a small cell structure of pulp and thick cell membranes. The strength of fruit also depends on the technology and conditions of cultivation, so, it decreases with an increase of the number of watering. The strength properties of fruit are usually evaluated by the resistance of skin and pulp to puncture [4].

Mechanical tomato varieties of domestic and foreign selection are grown in vegetablegrowing farms of Kuban. They differ from tomatoes of table varieties, first of all, higher strength characteristics of fruits. Thus, with permissible damage to tomatoes in 5\%, critical heights of falling on the wooden surface of tomatoes of mechanical varieties VF-145-E-B and Mashinny 1 will be 330 and $580 \mathrm{~mm}$, respectively, and for table tomatoes of variety Volgogradsky 5/95 - only $160 \mathrm{~mm}$ (Figure 1).

A feature of the mechanical harvesting of fruit of these varieties is that 10-15 days before the mass harvesting of the plantation, it is necessary to treat with the preparation Gidrel to cause the mass maturation. Such varieties as: Novichok, Mobil (Yugoslavia), Vineta. Vineta tomatoes provide with productivity to 700-900 c/ha. The effort of separation of tomatoes from stalks should be at least $7 \mathrm{H}$ and not more than $20 \mathrm{H}$. In varieties of tomatoes, which fruits are separated more easily, there is their shedding on the ground at the time of cutting the plants, so the losses are significant [5].

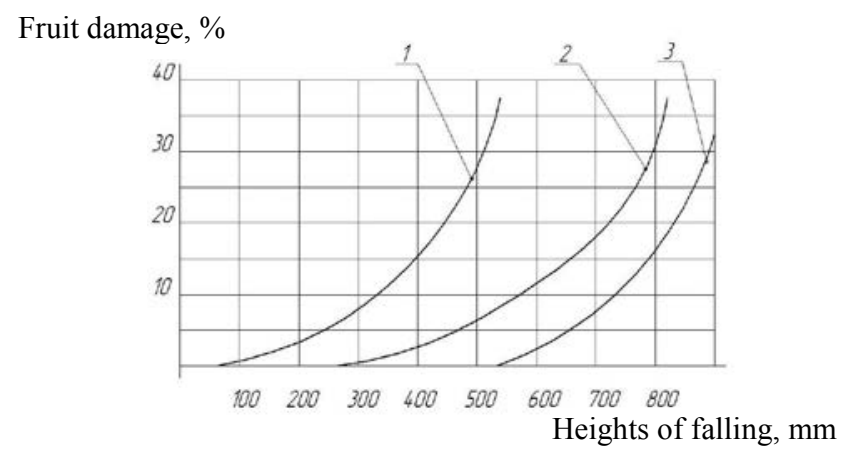

1- variety Volgogradsky 5/95; 2 - variety VF-145-E-B; 3 - variety Mashinniy 1

Fig. 1. Change of mature tomato damageability. 
For tomato varieties where the required effort for the separation of the fruit is $20 \mathrm{H}$ or more, a shaking device with a higher frequency and amplitude of oscillation, which can cause damage to fruit, is required. The lodging of shrubs is an essential physical and mechanical property. Varieties of tomatoes with stalk shrubs are too little. Usually the lodging rate is $40-45 \%$, despite the fact that it should not be more than $20-25 \%$ according agricultural requirements. The degree of lodging of plants depends on many factors, such as their variety, the stage of ripeness, the size of the shrub and others. Losses in the field which remain behind the harvester directly depend on the degree of plant lodging [6]. This phenomenon is negative at any harvesting technology. And for this reason the cutting devices of all harvesting machines are installed below the surface of the field, which dramatically increases the energy of the harvester as a whole. The simultaneity of fruit ripening is influenced by the characteristics of the variety and agricultural cultivation, as well as the uniformity of seeds or seedlings, the uniformity of moisture and fertilizer application, the uniformity of the soil in terms of mechanical composition. Maturation simultaneity is an indicator of uniformity of plant development. Exactly, it characterizes the suitability of varieties to mechanized technology of one-time harvesting.

The transportability of tomatoes, i.e. their ability to be remained in certain conditions, depends not only on the varietal characteristics, but also to a large extent on the quality of harvesting, packaging and transportation of tomatoes [7]. Tomatoes concern to Solanaceae which fruit mature simultaneously in natural conditions. There is a natural way of smoothing the maturing stage of all mass of fruit by the method of filling of plantation with special preparation. With this method of harvesting, the yield of the plantation is significantly reduced by $30-40 \%$ and fruit are suitable only for processing.

One-time harvesting of tomatoes is a one-time removal of all fruit from the plant. In this case, the shrub can be cut or left in the field. This method provides for pre-treatment of the plantation by a special technique that ensures rapid smoothing of all fruit by ripeness. Usually, one-time harvesting of tomatoes is carried out with the help of technical means. The harvester gathers all the fruit from shrubs, the vehicles move them to the clearing and sorting unit, and from there-for processing or to retail chains. In existing devices for onetime gathering of fruit, the process of fruit separation is carried out due to the direct impact of the working element on the fruit or due to the forces of inertia. In the first case, the fruit are separated by combing the shrubs with valves, spirals, rollers and other working elements. In the second case it occurs by pulling (shaking ) [8].

One of the first production machines for one - time harvesting of tomatoes was the machine SKT-2 made in Moldova. This machine provided the fruit separation by shaking pulling of shrubs of the plant. The combine harvester SKT-2 is self-propelled, designed to collect simultaneously ripening fruit for canning purposes and for the last gathering of tomatoes of table varieties [9].

The combine harvester works together with the transport truck PT-3,5, KSP-6, PV-3 and wheeled tractors of the type "Belarus".

The self-propelled tomato harvester SKT-2 (Figure 2) consists of a harvesting part 1, a fruit-separating group 2, a system for gathering green fruits 3 , a sorting table 4 , a separation table 5 , a chassis 6 .

For this purpose, there was proposed the developed design of the machine for repeated harvesting of nightshade vegetables, which was tested in the fields of Kuban State Agrarian University. The machine meets all agrotechnical requirements of the specified technological operation.

For reusable harvesting of tomatoes of table varieties on small plantations of farms there was developed, manufactured and tested the machine MT-1 (Figure 2) at the department of "Agricultural machines", now the department of "Processes and machines in agribusiness" of Kuban State Agricultural University. 
a

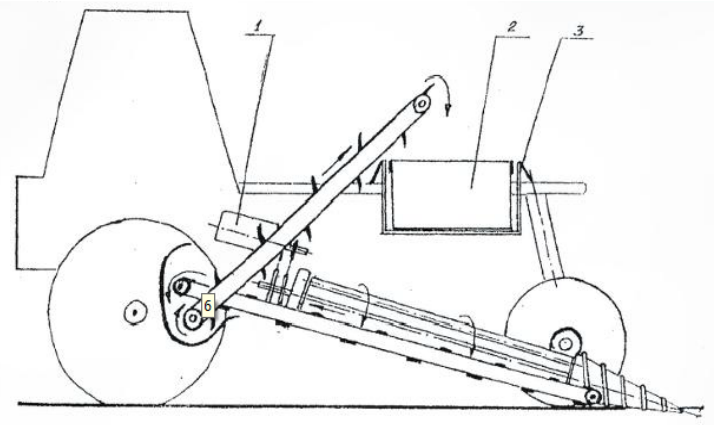

b

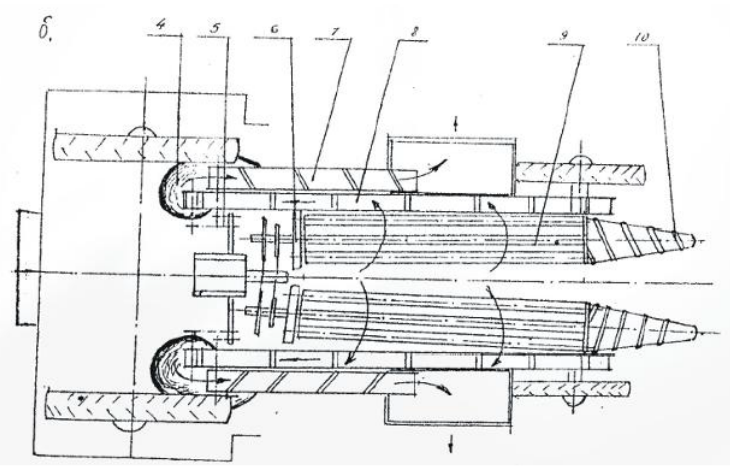

1 - driving plant, 2 - power unit, 3 - frame, 4 - drive of working elements, 5 - chain drive, 6 independent mechnism of drive, 7 - loading transporters, 8 - fruit separator transporters, 9 - twodrum multi-rolling fruit separator, 10 - active stalk lifters.

Fig. 2. Scheme of technological process of the machine MT-1 for reusable tomato harvesters: afrontal type; $b$ - top view

The machine MT-1 is a single-row, hung on a self-propelled chassis T-16 MT with high clearance. The basis of this machine is the double-drum planetary multi-rolling fruit separator 9, on which axis there were set the active stalk separators 10 with a spiral winding on each drum. There is a separate drive mechanism 6 on the rear side of each drum. These mechanisms are planetary or differential type, the elements of which are driven by two stars, each through the drive station and from the tractor PTO. Six small-diameter rollers are installed on the periphery of each drum, the drums have central shafts, pivotally connected to the stalk lifters 10. In direct closeness from the left and right fruit drums 9 there were installed the fruit conveyors 8 . They rest against the fruit tanks 4 in the back part. These transporters are made of rubberized fabric with activators and they are installed with fruit separators in parallel. Next to these conveyors, at an angle of $35^{\circ}$, loading conveyors 7 are installed, they were made of rubberized fabric, but with active finger fruit hooks with a height of $70 \mathrm{~mm}$. The drive of all conveyors is carried out by a chain transmission 5 through the drive station 1 from the tractor PTO [10].

Supported arms installed by standard boxes for gathering the fruit were set to the left and to the right on the chassis of the tractor. The design of the hinged device of the MT-1 machine is mobile and can be mounted (dismantled) in a short time.

According to the results of the performed work it is possible to draw some conclusions: one of the major conclusions is that the majority of machines is of foreign production. In the conditions of import substitution of foreign agricultural products and increasing the area of planting vegetables in the Russian Federation to create a safety cushion, the maximum mechanization of the technological process of harvesting vegetables will be undoubtedly 
required. As we can see, most of the machines are already obsolete and are not supplied to our domestic market.

In this regard, we consider it urgent to develop new types of machines for harvesting vegetables, which will meet all agricultural requirements and operating conditions.

\section{References}

1. Trubilin E.I., Belousov S.V., Lepshina A.I, Results of experimental studies determining the degree of traction resistance of the plowshoe in the treatment of heavy soils, The Political Network Electronic Scientific Journal of the Kuban State Agrarian University, No. 103, 673-686 (2014).

2. Trubilin E.I., Belousov S.V., Lepshina A.I. Economic efficiency of the dump cultivation of soil developed by a combined plowshoe, The political network electronic scientific journal of the Kuban State Agrarian University, No. 103, 654-672 (2014).

3. Trubilin E.I., Belousov S.V., Lepshina A.I., The main soil cultivation with the formation turnover in modern working conditions and devices for its implementation, The political network electronic scientific journal of the Kuban State Agrarian University, No. 104, 1902-1922 (2014).

4. Belousov S.V. Communication of science and technology in the field of development of machines for the basic tillage of the soil with the circulation of the bed, The political network electronic scientific journal of the Kuban State Agrarian University, No. 109, 468-486 (2015).

5. Belousov S.V. Modern technologies of soil cultivation, Scientific provision of the agro industrial complex, FROM. 3-4 (2012).

6. Parkhomenko GG, Bozhko I.V., Semenikhina Y.A., Pantyukhov I.V., Drozdov S.V., Gromakov A.V., Kambulov S.I., Belousov S.V, Perfection of working organs for tillage, State and prospects of the development of agricultural machinery. Collection of articles of the 9th international scientific and practical conference within the framework of the 19th international agro-industrial exhibition "Interagro-mash-2016", FROM. 27-30 (2016).

7. Belousov S.V., Trubilin E.I., Development of the construction of a plow for the treatment of heavy soils / // Science of the Kuban, No 1, 37-40 (2013).

8. Belousov S.V. Patent search for structures that provide soil treatment with the turnover of the reservoir. Search method. The proposed technical, The political network electronic scientific journal of the Kuban State Agrarian University, No. 109, 416-450 (2015).

9. Belousov S.V. Decrease in energy intensity of the process of basic processing of soil with turnover of the bed, Fundamental foundations of modern agrarian technologies and technology. Collection of works of the All-Russian Youth Scientific and Practical Conference. -National Research Tomsk Polytechnic University, FROM. 280-283 (2015).

10. Belousov S.V. Role and prospects for the development of small-scale mechanization in the context of co-temporary engineering, Scientific support of the agro-industrial complex. A collection of articles on the materials of the 72nd Scientific and Practical Conference of pre-applicants on the results of research work for 2016 -2017, 277-278. 